\title{
A case of perforation of rectum due to self-administered enema in a pregnant woman
}

\author{
Anjali Rani*, Puneet Gupta
}

\author{
Department of Obstetrics \& Gynaecology, Institute of Medical Sciences, Banaras Hindu University, Varanasi-221005 \\ Uttar Pradesh, India
}

Received: 10 June 2014, Revised: 2 July 2014

Accepted: 3 July 2014

\author{
*Correspondence: \\ Dr. Anjali Rani, \\ E-mail: anjaliraniimsbhu@gmail.com
}

(C) 2014 Rani A et al. This is an open-access article distributed under the terms of the Creative Commons Attribution Non-Commercial License, which permits unrestricted non-commercial use, distribution, and reproduction in any medium, provided the original work is properly cited.

\begin{abstract}
A 23 year old primigravida at 35 weeks gestation presented with pain abdomen, fever and dissension of abdomen. Initially patient was managed conservatively at peripheral centre for two days and then reported to our hospital. An ultrasound done which shows collection inside peritoneal cavity and perforation was suspected. Decision of laparotomy was done. First caesarean section was done and a single live male baby born weighing $2.4 \mathrm{~kg}$ born. Then on exploration a small perforation in rectum was found and it was repaired by surgeon. But they found two more perforations and colostomy was done. On taking detailed history patient told that she-herself administered enema because of constipation. In post op period patient expired because of septicemia and ARDS.
\end{abstract}

Keywords: Perforation, Rectum, Pregnancy, Enema

\section{INTRODUCTION}

Rectal perforations are very rare. The morbidity and mortality is very high in rectal perforation. Enema should never be given in case of impacted stool. But because of ignorance this patient applied enema herself. So, simply awareness about enema indications and contraindication would have avoided this problem and unnecessary mortality in a young patient. A little knowledge is a dangerous thing. So, patient education should be done.

\section{CASE REPORT}

A 23 year old female at 35 weeks of gestation presented with complain of pain abdomen, fever and constipation. Patient was initially managed at periphery by analgesics and antibiotics. Then she was referred in our hospital. Patient was admitted and investigated. Her hemoglobin was $10 \mathrm{gm} / \mathrm{dl}$. Total leucocyte count was 18000 . In her USG abdomen there was collection inside the peritoneal cavity. Intestinal perforation was suspected. Case discussed with surgeon and plan of first to do caesarean section and then to search for perforation.

Caesarean section was done and a single live male baby born. Baby cried immediately after birth. Weight of baby was $2.4 \mathrm{~kg}$. Placentae was delivered and uterus was stitched in layers. Then on exploration there was no perforation in small intestine. But to our surprise there was small perforation in rectum as shown in Figure 1. Repair of perforation was done by surgeon as shown in Figure 2. But there were two more perforation in rectum which were sutured and then colostomy was done. Whole of the peritoneal cavity was filled with foul smelling fluid and fecal matter. Peritoneal lavage was done with normal saline. Drain was put inside peritoneal cavity. Patient was given two units of blood transfusion. Again we took detailed history from attendants and found that patient had herself administered enema at home. This may be the cause of perforation of rectum. There was no h/o typhoid fever in the past. 
In post-operative period patient developed high grade fever and dyspnoea. In chest there were crepts. Patient developed ARDS and septicemia. On $4^{\text {th }}$ postoperative day patient expired.

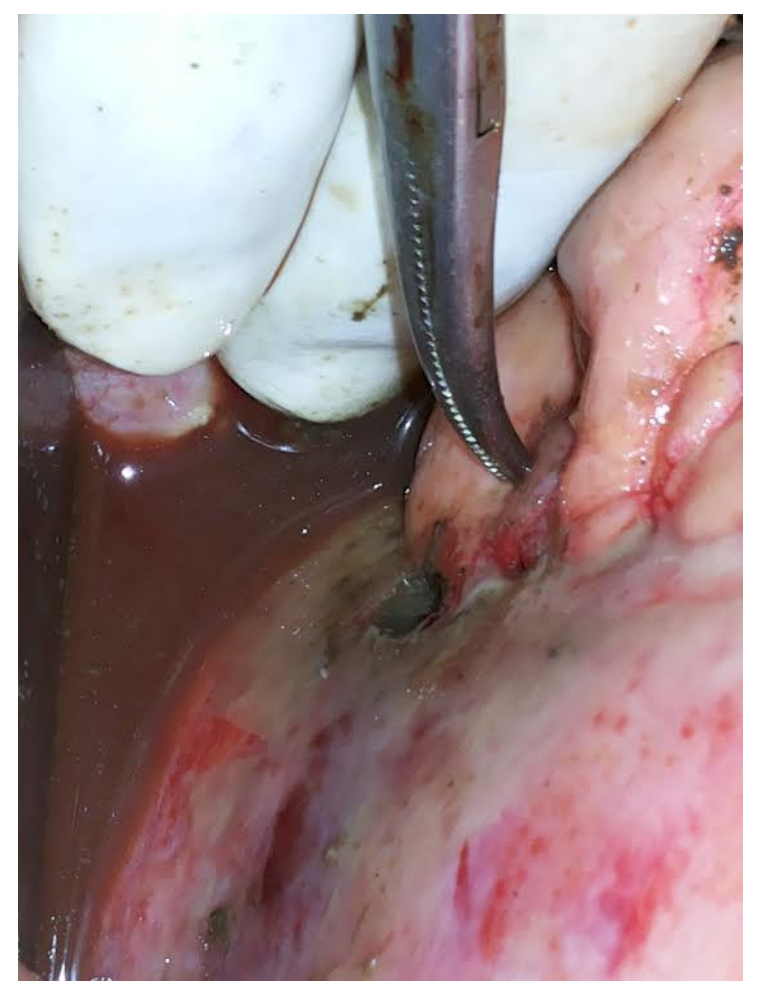

Figure 1: Showing small perforation in rectum.

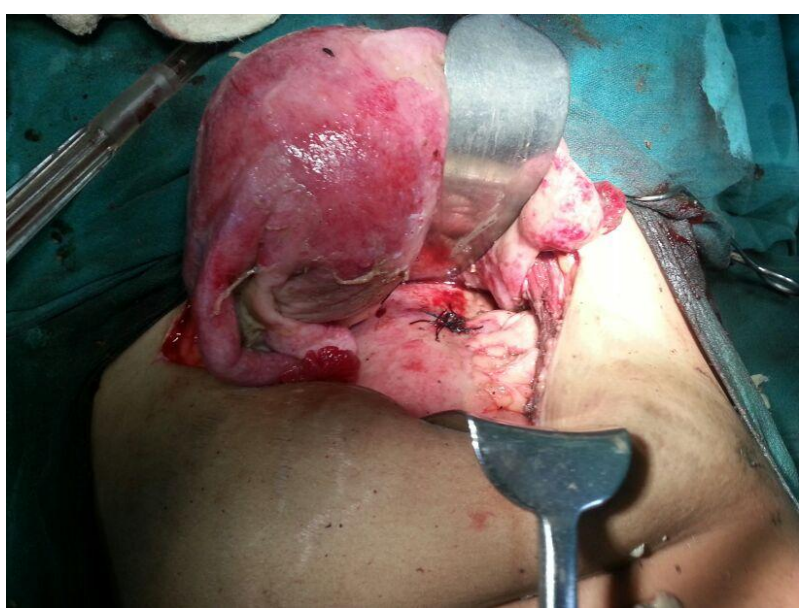

Figure 2: Repair of perforation was done by surgeon.

\section{DISCUSSION}

Rectal perforation leading to death in a young patient due to self-administered enema is very unfortunate. A little ignorance has caused this event. Once peritonitis develops due to rectal perforation death is inevitable. Then proper referral in time should be there. Patient lost 2 days in delaying treatment at periphery and in mean time she developed peritonitis and which caused death in patient. So in acute abdomen we should take a detailed history which can help us to make early diagnosis and timely treatment.

\section{Funding: No funding sources}

Conflict of interest: None declared

Ethical approval: Not required

\section{REFERENCES}

1. Klein RR, Scarborough RA. Traumatic perforations of the rectum and distal colon. Am J Surg. 1953;86:515.

2. Andrews EW. Pneumatic rupture of the intestine: a new type of industrial accident. Surg Gynaecol Obstet. 1911;12:63.

3. Charles G. Roland, Arnold G. Rogers. Rectal perforations after enema administration. Can Med Assoc J. 1959 Nov;81(10):815-8.

4. Kume K, Watanabe T, Oshima J, Yoshikawa I, Harada M. Rectal perforation caused by mesalazine enema in a patient with ulcerative colitis. Endoscopy. 2014;46(Suppl 1) UCTN:E190.

5. Kalkan IH, Oztas E, Yildiz H, Beyazit Y, Suvak B, Boyabatli M. Rectal perforation as a result of selfadministration of retrograde enema in an elderly dementia patient. Geriatr Gerontol Int. 2012 Jul;12(3):564-5.

6. Mori H, Kobara H, Fujihara S, Nishiyama N, Kobayashi M, Masaki T, et al. Rectal perforation and fistulae secondary to a glycerin enema: closure by over-the-scope-clip. World J Gastroenterol. 2012 Jun;18(24):3177-80.

7. Tanswell IJ, Irfan K, Kossakowski T, Townson G. Rectal perforation in ulcerative colitis: complication of an enema tip. Gastrointes Endosc. 2009 Feb;69(2):344.

DOI: $10.5455 / 2320-1770$. ijrcog20140922

Cite this article as: Rani A, Gupta P. A case of perforation of rectum due to self-administered enema in a pregnant woman. Int J Reprod Contracept Obstet Gynecol 2014;3:783-4. 